\title{
Facets of impulsivity and related aspects differentiate among recreational and unregulated use of Internet pornography
}

\author{
STEPHANIE ANTONS ${ }^{1}$, SILKE M. MUELLER ${ }^{1}$, ELISA WEGMANN ${ }^{1}$, PATRICK TROTZKE $^{1}$, MAX M. SCHULTE $^{1}$ and \\ MATTHIAS BRAND ${ }^{1,2 *}$ \\ ${ }^{1}$ General Psychology: Cognition and Center for Behavioral Addiction Research (CeBAR), University of Duisburg-Essen, \\ Duisburg, Germany \\ ${ }^{2}$ Erwin L. Hahn Institute for Magnetic Resonance Imaging, Essen, Germany
}

(Received: November 23, 2018; revised manuscript received: March 22, 2019; accepted: April 7, 2019)

\begin{abstract}
Background and aims: Unregulated Internet pornography (IP) use is discussed as a clinically significant disorder. Because of its primarily rewarding nature, IP is a predestinated target for addictive behaviors. However, not every user develops an unregulated usage pattern. In fact, most users tend to use IP recreationally. Impulsivity-related constructs have been identified as promoters of addictive behaviors. It is unclear whether these impulsivity-related constructs are specific for unregulated IP use or also play a role in recreational but frequent behaviors. In this study, we investigated impulsive tendencies (trait impulsivity, delay discounting, and cognitive style), craving toward IP, attitude regarding IP, and coping styles in individuals with recreational-occasional, recreational-frequent, and unregulated IP use. Methods: A total of 1,498 heterosexual males participated in an online survey. Groups of individuals with recreational-occasional use $(n=333)$, recreational-frequent use $(n=394)$, and unregulated use $(n=225)$ of IP were identified by screening instruments. Results: Craving and attitude regarding IP as well as delay discounting and cognitive and coping styles differed between groups. Individuals with unregulated use showed the highest scores for craving, attentional impulsivity, delay discounting, and dysfunctional coping, and lowest scores for functional coping and need for cognition. Recreational-frequent users had the most positive attitude toward IP. Motor and non-planning impulsivity did not differ between groups. Discussion and conclusions: The results indicate that some facets of impulsivity and related factors such as craving and a more negative attitude are specific for unregulated IP users. The results are also consistent with models on specific Internet use disorders and addictive behaviors.
\end{abstract}

Keywords: Internet pornography use disorder, impulsive behavior, behavioral addiction, compulsive sexual behavior

\section{INTRODUCTION}

Unregulated Internet pornography (IP) use is currently discussed as a clinically significant mental disorder (Kraus et al., 2018). Since similar mechanisms are involved in the development and maintenance of unregulated IP use and substance use disorders, some authors argue for a classification as a disorder due to addictive behaviors (Gola et al., 2017; Love, Laier, Brand, Hatch, \& Hajela, 2015; Potenza, Gola, Voon, Kor, \& Kraus, 2017; Young, 2008). Especially, because of its primarily rewarding nature, IP is a predestinated target for addictive behaviors. However, not every user, even while consuming IP frequently, develops an unregulated IP use which is accompanied by experiences of negative consequences in daily life. In fact, most individuals using IP show a recreational IP use without having a problematic usage pattern that results in distress or negative consequences (Cooper, Morahan-Martin, Mathy, \& Maheu, 2002).

Impulsivity and related factors, such as trait impulsivity (e.g., Billieux, Gay, Rochat, \& Van der Linden, 2010), craving (e.g., Rosenberg \& Mazzola, 2007; Starcke, Antons,
Trotzke, \& Brand, 2018), attitude (Berridge \& Robinson, 2016), and a dysfunctional or less functional style to cope with affective mood states or the intense urge to engage in certain behaviors (e.g., Hasking, Lyvers, \& Carlopio, 2011; Jauregui, Onaindia, \& Estévez, 2017), have been identified as promoters of unregulated and addictive behaviors. The Interaction of Person-Affect-Cognition-Execution model of specific Internet-use disorders (I-PACE model; Brand, Young, Laier, Wölfling, \& Potenza, 2016) explains how these factors (among others) are involved in the development and maintenance of unregulated Internet use (e.g., IP, Internet gaming, and Internet shopping). The general tendency to act impulsively is a trait variable in the I-PACE model and is considered as a predisposing variable contributing to the development of a specific Internet use disorder.

\footnotetext{
* Corresponding author: Prof. Dr. Matthias Brand; General Psychology: Cognition and Center for Behavioral Addiction Research, University of Duisburg-Essen, Forsthausweg 2, 47057 Duisburg, Germany; Phone: +49 203 3792541; Fax: +49 203 3791846; E-mail: matthias.brand@uni-due.de
}

This is an open-access article distributed under the terms of the Creative Commons Attribution-NonCommercial 4.0 International License, which permits unrestricted use, distribution, and reproduction in any medium for non-commercial purposes, provided the original author and source are credited, a link to the CC License is provided, and changes - if any - are indicated. 
In the I-PACE model, craving is considered as an important aspect of the affective and cognitive responses to external or internal triggers, and is assumed to be developed through conditional learning processes. These affective and cognitive responses interact with Internet-related cognitive biases (e.g., positive associations or attitude) and dysfunctional or less functional coping styles, resulting in the decision to use a certain application. The use of an application itself may have a gratifying effect, which can reinforce affective and cognitive responses, cognitive biases, and coping style and which again may enhance the chance that individuals decide to use the application. The frequent repetition of these mechanisms may then lead to the development of an unregulated use of specific Internet applications with diminished control over the use and a continued use despite negative consequences. Nevertheless, facets of impulsivity and related factors, such as craving, positive attitude, and dysfunctional or less functional coping styles, can also occur in recreational and non-addictive behaviors (Dickman, 1990; Jentsch et al., 2014). This raises the question which impulsivity-related factors are specific for unregulated IP use.

With regard to a general tendency to act impulsively, research indicates that unregulated IP use is at least weakly associated with higher levels of trait impulsivity (Antons \& Brand, 2018; Böthe et al., 2018; Wéry, Deleuze, Canale, \& Billieux, 2017). This might indicate that trait impulsivity is a predisposing factor for unregulated IP use but might not be the aspect that differentiates the best between recreational and unregulated IP use (also see Böthe et al., 2018). In addition, the frequency of IP use in general (regardless of the IP use being recreational or unregulated) has been shown to be correlated with impulsive choice tendencies indicated by a preference for smaller immediate over larger subsequent rewards, thus high delay discounting (Negash, Sheppard, Lambert, \& Fincham, 2016). Both recreational and unregulated IP use were associated with craving toward IP use. However, the results for recreational IP use were rather inconsistent (Hald \& Malamuth, 2008; Rosenberg \& Kraus, 2014; Wetterneck, Burgess, Short, Smith, \& Cervantes, 2012), while higher craving was consistently associated with a higher symptom severity of unregulated IP use (e.g., Antons \& Brand, 2018; Gola et al., 2017; Kraus, Meshberg-Cohen, Martino, Quinones, \& Potenza, 2015; Laier, Pawlikowski, Pekal, Schulte, \& Brand, 2013; Weinstein, Zolek, Babkin, Cohen, \& Lejoyeux, 2015). With regard to cognitive biases and the attitude toward IP, it has been shown that unregulated IP use was associated with more positive implicit associations (Snagowski, Wegmann, Pekal, Laier, \& Brand, 2015) and both approach (indicating a positive attitude) and avoidance tendencies (indicating a negative attitude) toward IP images (Snagowski \& Brand, 2015). Furthermore, Brown, Conner, and Vennum (2017) could show that the acceptance of pornography and a general sexual permissiveness were associated with higher IP use. In addition, a more positive attitude toward IP has been associated with frequent IP use (Svedin, Akerman, \& Priebe, 2011). Evidence is weak regarding the relationship between unregulated or recreational IP use and coping styles. Although different authors emphasize that coping with averse affective states might be a motive for using IP
(Franc et al., 2018; Reid, Li, Gilliland, Stein, \& Fong, 2011), only one study identified dysfunctional coping as a determinant of unregulated IP use (Laier, Pekal, \& Brand, 2015).

Systematic investigations of facets of impulsivity and related factors as differential aspects between individuals with recreational and unregulated IP use are unavailable. In this study, we distinguished between three types of IP users, namely individuals with recreational-occasional, recreational-frequent, and unregulated IP use. We expect the different types of IP users to differ with regard to the following facets of impulsivity and related factors: general tendencies to act impulsively (indicated by trait impulsivity, delay discounting, and cognitive style), craving toward IP, attitude toward IP, and coping styles. We presume that individuals with uncontrolled IP use score higher on impulsivity-related aspects compared to individuals with recreational IP use.

\section{METHODS}

\section{Participants}

Since IP use might differ between sociocultural groups (Cooper, Putnam, Planchon, \& Boies, 1999), we focused on a homogenous group of heterosexual males in the context of this study. Participants were recruited online via invitations per e-mail and postings on social networking sites as well as offline via local advertisements at the university and nation-wide newspaper articles. All participants were given the opportunity to participate in a lottery to win 1 out of 13 vouchers valued between $15 €$ and $100 €$ as incentive for their participation.

The initial sample of the online survey consisted of 1,640 heterosexual male IP users (age: $M=31.76, S D=11.26$, range: $18-83$ years), who completed the survey without missing data. We identified careless respondents by analyzing response times and response patterns using methods as recommended by Curran (2016) and Meade and Craig (2012). After careful consideration, the authors excluded 142 participants, resulting in a sample consisting of 1,498 participants (see Supplementary Material for detailed description of this procedure).

\section{Measures}

Symptom severity of unregulated IP use. The 12-item German short Internet Addiction Test (Pawlikowski, Altstötter-Gleich, \& Brand, 2013) modified for IP (s-IATporn; Laier et al., 2013) assesses symptom severity of unregulated IP use with two subscales. The first subscale is control/time management (e.g., "How often do you find that you stay on Internet pornography sites longer than you intended?"). Cronbach's $\alpha$ in this sample was .87. The second subscale is craving/social aspects (e.g., "How often do you choose to spend more time on Internet pornography sites over going out with others?"). Cronbach's $\alpha$ in this sample was .81. Items were answered on a 5-point Likert scale (ranging from $1=$ never to $5=$ very often). Thus, the s-IATporn sum score possibly ranges between 12 and 60 . The Cronbach's $\alpha$ for the sum score was .90 in this sample. Following the recommendations by Laier et al. (2013) and 
Pawlikowski et al. (2013), an s-IATporn sum score $\leq 30$ defines the relevant cut-off score for (non-problematic) recreational IP use, whereas an s-IATporn sum score $>37$ indicates unregulated/pathological IP use. Values between these two cut-off scores describe a problematic IP use.

Problematic use of further specific Internet applications. Four anchor items of the German short Internet Addiction Test (Pawlikowski et al., 2013) were used to assess problematic use of Internet-shopping, Internet-gaming, and Internet-gambling applications/sites, as suggested by Müller et al. (2017). Items were rated on a 5-point Likert scale (ranging from $1=$ never to $5=$ very often) resulting in a sum score for symptom severity of unregulated use of further specific Internet applications between 12 and 60 .

IP use (min/week). IP usage time was assessed by two questions (Antons \& Brand, 2018): (a) How many times do you use IP within a week? (average frequency in 7 days) and (b) how long do you usually use IP within one session? Both questions were answered with numeric values. The product term of these two answers is used as an approximation of the amount of time spent using IP during 1 week. Furthermore, participants were asked at what age they used IP for the first time.

Trait impulsivity. The 15-item German short version of the Barratt Impulsiveness Scale (BIS-15; Meule, Vögele, \& Kübler, 2011) measures non-planning (e.g. "I plan for job security," Cronbach's $\alpha$ in this sample is .80), motor (e.g., "I do things without thinking," Cronbach's $\alpha$ in this sample is .79), and attentional impulsivity (e.g., "I am restless at the theatre or lectures," Cronbach's $\alpha$ in this sample is .65). Because of skewed data, we also calculated reliability with the greatest lower bound (GLB) method, as recommended by Trizano-Hermosilla and Alvarado (2016), resulting in a reliability score of 0.71 . Items were answered on a 4-point Likert scale (ranging from $1=$ rarely/never to $4=$ almost always/always). Each subsum score ranges from 5 to 20 , with higher scores indicating higher trait impulsivity.

\section{Delay discounting}

Tendencies toward impulsive choices were assessed with the Monetary Choice Questionnaire (MCQ; Kirby, Petry, \& Bickel, 1999). The MCQ provides a measure of an individual delay discounting rate ( $\kappa)$ using 27 items. Participants had to repeatedly decide between a small immediate monetary reward and a larger delayed monetary reward (e.g., "Would you prefer $15 €$ today or $35 €$ in 13 days?"). The $\kappa$ values were transformed using the natural logarithm $\ln (\kappa)$, in order to perform parametric testing. Higher values indicate higher tendencies toward impulsive choices, since it represents a preference for smaller immediate over larger subsequent rewards.

\section{Cognitive styles}

The Rational-Experiential Inventory (REI; Epstein, Pacini, Denes-Raj, \& Heier, 1996) in a German version (Keller, Bohner, \& Erb, 2000) measures cognitive styles on two subscales: faith in intuition comprising 15 items (e.g., "I believe in trusting my hunches," Cronbach's $\alpha$ in this sample is .87) and need for cognition comprising 17 items (e.g.,
"I would prefer complex to simple problems," Cronbach's $\alpha$ in this sample is .86). Items were answered on a 7-point Likert scale (ranging from $1=$ totally incorrect to $7=$ totally correct). Higher scores on the scale faith in intuition as well as lower scores on the need for cognition scale indicate a less reflective and a more impulsive information processing style.

\section{Craving toward IP use}

The Craving Assessment Scale for Behavioral Addictions (CASBA) specified for pornography was used to measure baseline craving as the actual urge to use IP. The CASBAporn is a new screening tool, which was developed due to a lack of theory-based measurements for the assessment of craving. Following theoretical approaches by different authors (Tiffany \& Drobes, 1991; Verheul, van den Brink, \& Geerlings, 1999), the questionnaire aims to assess reward craving (e.g. "Using Internet pornography now would give me satisfaction"), relief craving (e.g., "Using Internet pornography now would make me less stressed"), and obsessive craving (e.g., "Using Internet pornography now is the most urgent thing I want to do") with nine IP-specific items. All items were rated on a 5-point Likert scale (ranging from $1=$ completely disagree to $5=$ completely agree) resulting in sum scores ranging between 9 and 45. Experts in this field rated the representability and validity of the items and a confirmatory factor analysis of the scales is currently under validation. The internal consistency in this sample is excellent with Cronbach's $\alpha=.88$. It has to be emphasized that the CASBA-porn measures actual craving/ urge to use pornography in the current situation. On the contrary, the s-IATporn factor craving and social problems measures problems related to craving, preoccupation, and social conflicts due to (excessive) pornography use.

\section{Attitude toward IP}

Participants rated their attitude toward IP on a 5-point Likert scale ranging from 1 (negative) to 5 (positive).

\section{Coping styles}

Functional and dysfunctional coping styles were assessed via the German version (Knoll, Rieckmann, \& Schwarzer, 2005) of the Brief Cope (Carver, 1997), which measures coping styles in several subdomains. Each subscale consists of two items, which were answered on a 4-point scale (ranging from $1=$ I haven't been doing this at all to $4=$ I've been doing this a lot). Based on previous work (Brand, Laier, \& Young, 2014; Wegmann \& Brand, 2016), dysfunctional coping was assessed by the three subscales: denial (e.g., "I've been saying to myself 'this isn't real"'), substance use (e.g., "I've been using alcohol or other drugs to make myself feel better"), and behavioral disengagement (e.g., "I've been giving up trying to deal with it"). In the current sample, dysfunctional coping has a low internal consistency with Cronbach's $\alpha=.70$. Since data for most items were skewed, we calculated additional reliability with the GLB method (Trizano-Hermosilla \& Alvarado, 2016), resulting in a reliability estimate of .84 . 
Five subscales were used to assess functional coping: active coping (e.g., "I've been taking action to try to make the situation better"), instrumental support (e.g., "I've been getting help and advice from other people"), emotional support (e.g., "I've been getting emotional support from others"), planning (e.g., "I've been thinking hard about what steps to take"), and positive reframing (e.g., "I've been looking for something good in what is happening"). In the current sample, functional coping has an acceptable internal consistency with Cronbach's $\alpha=.84$.

\section{Procedure}

The questionnaires were presented as an online survey in the following order: demographic variables, CASBA, MCQ, Brief COPE, s-IATporn, s-IAT anchor items, BIS-15, REI, IP use (min/week), and their attitude toward IP use.

\section{Statistical analyses}

All statistical analyses were calculated using SPSS for Windows (version 24, IBM Corp., Armonk, NY, USA). One-way analyses of variance (ANOVAs) were used to explore differences between IP user groups with regard to s-IATporn score, IP use, age, and age of first use. In case of variance inhomogeneity, the corrected Welch's $F$ was used. For post-hoc tests, Bonferroni-correction was used. Effect sizes for the ANOVAs are reported by eta squared $\left(\eta^{2}\right)$. A $\chi^{2}$ test was used to analyze group differences in relationship status. One-way analyses of covariance (ANCOVAs) were used to explore differences between IP user groups in tendencies to act impulsively (BIS-15, MCQ, and REI), craving, attitudes toward IP, and coping styles. Age, relationship status, and the s-IAT anchor item sum score were entered as covariates. Effect sizes are reported by partial eta squared $\left(\eta_{\mathrm{p}}{ }^{2}\right)$, for the single comparisons by Cohen's $d$.

\section{Ethics}

All participants were fully instructed and gave informed consent prior to the investigation. The study was approved by the local ethics committee.

\section{RESULTS}

\section{Characteristics of groups representing different types of IP use}

Correlations between s-IATporn scores as well as IP use measures and variables of interest over the whole sample are presented in Table 1.

To form the groups according to the IP-use patterns, we grouped individuals with recreational (s-IATporn sum $\leq 30$; $n=1,000)$ and unregulated (s-IATporn sum $>37 ; n=253$ ) IP use. Individuals with problematic use $(n=245$; s-IATporn sum between 31 and 37) were excluded in order to have a distinct separation between users with recreational and unregulated use. Second, we identified individuals with recreational-occasional and recreational-frequent IP use by

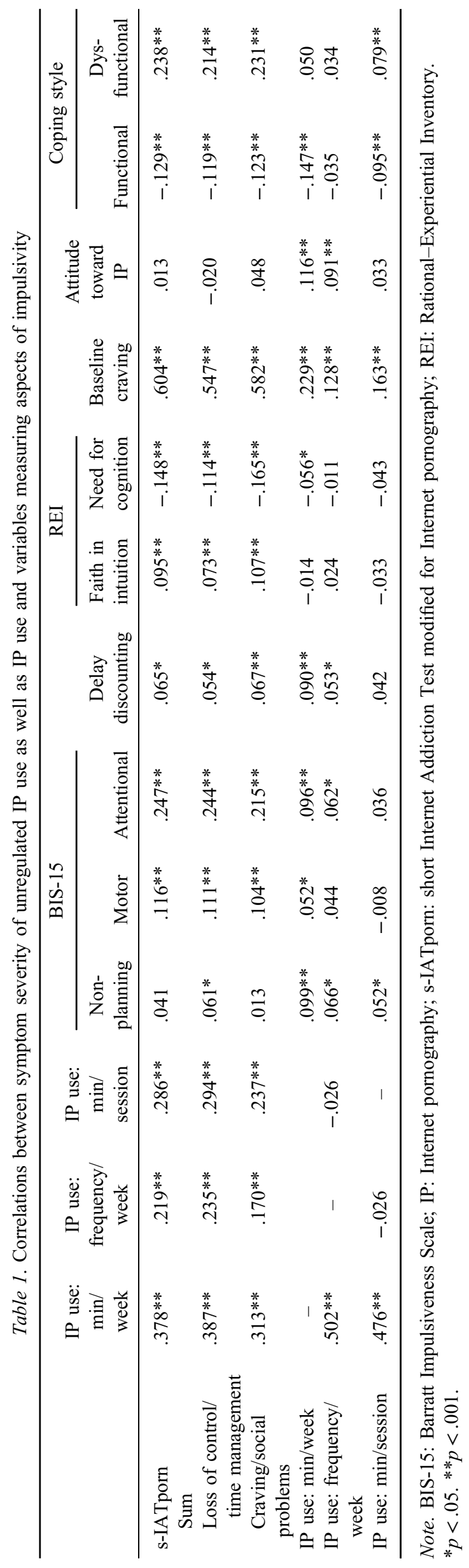


taking the lower and upper $30 \%$ of the estimated IP use (min/week) distribution in all individuals with recreational use as cut-off scores, that is, occasional: IP use $\leq 74 \mathrm{~min} /$ week, frequent: IP use $\geq 160 \mathrm{~min} /$ week. This sample-based approach was used since concrete cut-offs for defining frequent IP use are unavailable. The upper cutoff was also applied for the individuals with unregulated use, since some individuals experience problems due to their IP use, but not due to an unregulated use (Grubbs \& Perry, 2018). This procedure led to the exclusion of 30 participants of the unregulated group with an IP use ranging from 4 to $150 \mathrm{~min} /$ week.

The descriptive statistics and ANOVA results for the three groups are presented in Table 2. As expected and at least partially as a result of the procedure of group definition, the three groups significantly differed in s-IATporn sum scores and IP use (min/week). It has to be emphasized that also recreational-frequent users showed significantly higher s-IATporn sum scores compared to the recreationaloccasional users, mean $_{\text {diff }}=-4.02, p<.001, d=0.88$, although both groups were under the cut-off for problematic IP use (s-IATporn sum $\leq 30$ ). Groups also significantly differed in frequency per week and minutes per session. Interestingly, the effect size of the post-hoc test between the individuals with recreational-frequent and unregulated use is descriptively higher for the duration per session $(d=0.39)$ compared to the frequency per week $(d=0.19)$.

Furthermore, the groups differed significantly in age. Post-hoc tests revealed significant age differences only between the recreational-occasional and recreationalfrequent users, mean $_{\text {diff }}=-2.32, p<.05, d=0.20$. Groups did not differ with regard to relationship status and age of first IP use.

\section{Group differences in variables related to impulsivity}

The results of ANCOVAs are presented in Table 3. With regard to facets of trait impulsivity, the groups did not differ in non-planning and motor impulsivity, but in attentional impulsivity, however, with a small effect size (Figure 1A-C). Individuals with unregulated use had the highest attentional impulsivity and significantly differed from both groups with recreational use.

The groups differed in impulsive choice indicated by the delay discounting rate with small effect size (Figure 2). Individuals with unregulated use showed significantly higher impulsive choice compared to those with recreationaloccasional use. Regarding cognitive style, we found significant but small differences in need for cognition (Figure 3A), but no significant differences in faith in intuition. The posthoc tests for need for cognition revealed significant differences between both recreational use groups and individuals with unregulated use with lower need for cognition in the group with unregulated use.

The groups significantly differed in baseline craving toward IP. Figure 4A illustrates that individuals with unregulated use scored highest on baseline craving followed by the recreational-frequent and recreational-occasional users with all group differences being significant. The attitude toward IP also differed between groups, and was highest (most positive) for the recreational-frequent users,

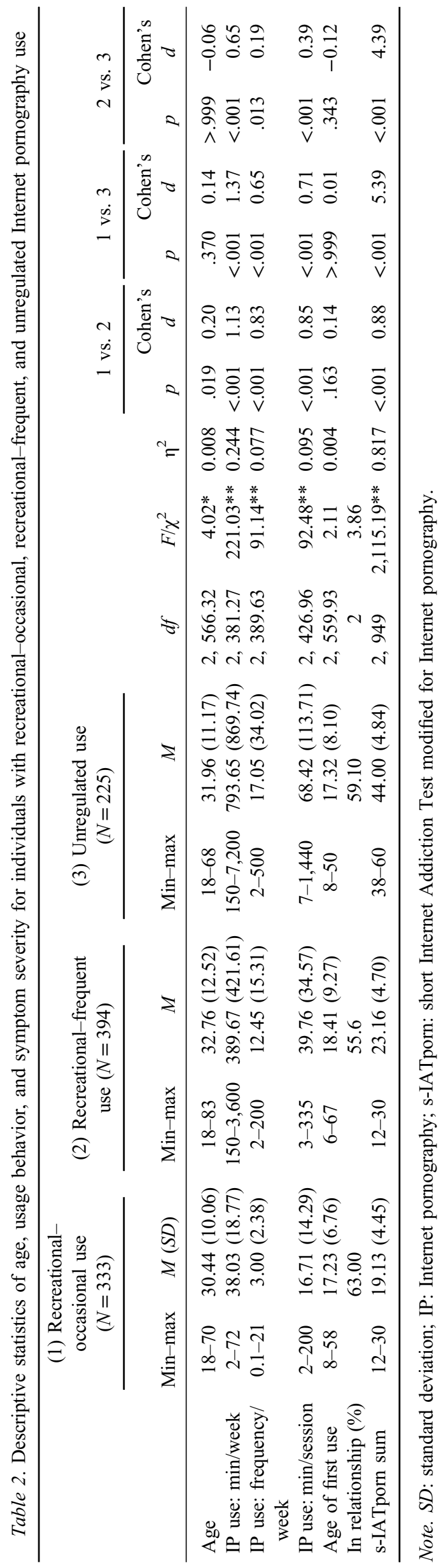




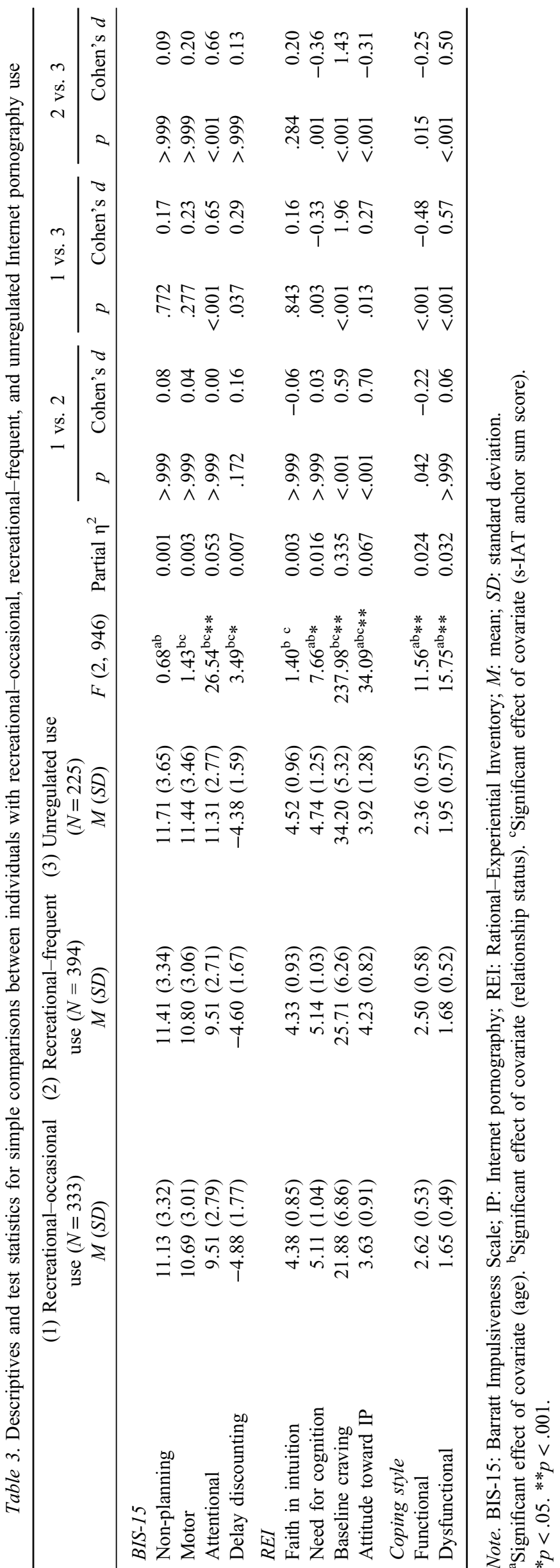

followed by the group with unregulated use and the group with recreational-occasional use (Figure 4B).

With regard to coping styles, we found significant differences again with small group effects (Figure 5A and B). Both recreational use groups differed from the unregulated use groups in both types of coping styles, with lower functional and higher dysfunctional coping styles in the unregulated group. In addition, the recreational-frequent users showed significantly lower functional coping styles compared to the individuals with recreationaloccasional use.

\section{DISCUSSION}

We investigated the differential facets of impulsivity and related factors, that is, general tendencies to act impulsively (indicated by trait impulsivity, delay discounting, and cognitive style), craving and attitudes toward IP, as well as coping styles, between individuals with recreationaloccasional, recreational-frequent, and unregulated IP use. Individuals with unregulated IP use had significantly higher scores in attentional impulsivity, baseline craving, and dysfunctional coping style as well as a lower functional coping style and need for cognition compared to both groups with recreational use. Groups also differed in their attitudes toward IP. The recreational-frequent users showed the most positive attitudes and the recreational-occasional users the most negative attitudes.

In more detail, individuals with unregulated use had significantly higher craving toward IP use than recreationaloccasional and recreational-frequent users. Individuals with recreational-occasional IP use showed the lowest craving levels and significantly differed from those with recreational-frequent usage and individuals with unregulated use. This is consistent with assumptions of the I-PACE model (Brand, Young, et al., 2016) and replicates results from previous studies on unregulated and recreational IP use (e.g., Antons \& Brand, 2018; Kraus et al., 2015; Laier et al., 2013; Weinstein et al., 2015). In this study, we could first show that males with frequent but recreational (unproblematic) IP use also have a lower level of craving compared to males with unregulated IP use, indicating that extreme high craving is specific for unregulated IP use, but not for high-frequent use per se.

Furthermore, individuals with unregulated IP use had a more negative attitude toward IP compared to the recreationalfrequent users. This result might suggest that individuals with unregulated IP use have a high motivation or urge to use IP, although they may have developed a negative attitude toward IP use, perhaps because they have already experienced negative consequences linked to their IP use pattern. This is consistent with the incentive-sensitization theory of addiction (Berridge \& Robinson, 2016), which proposes a shift from liking to wanting during addiction.

With regard to facets of impulsivity, especially attentional impulsivity and low need for cognition differentiated between unregulated and recreational use. Impulsive choice behavior only differed between recreational-occasional users and unregulated users. Therefore, it might be a general aspect of impulsive IP use. However, effect sizes were low 


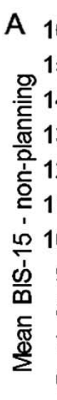

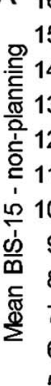

15
14
13
12
11
10
9
8
7
6
5 (1) Recreationaloccasional use
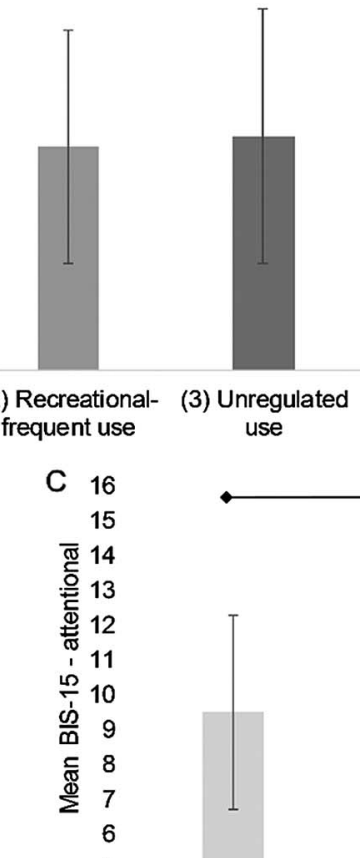

B 16

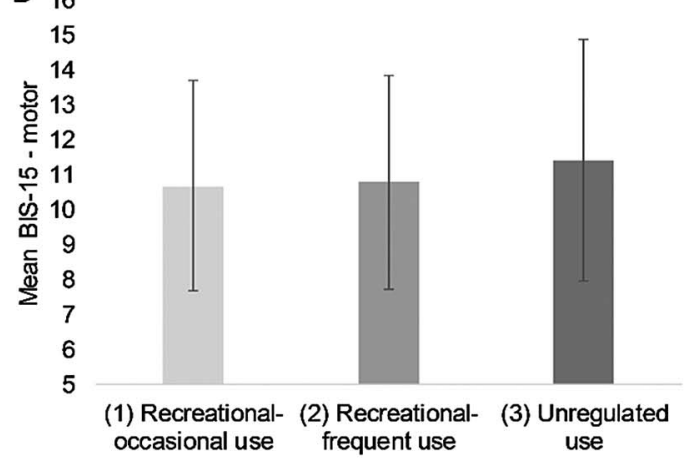

Figure 1. Mean values of BIS-15 subscales for groups of Internet pornography users. Significant differences are indicated by the horizontal bars. Standard deviations are represented by the error bars attached to each column. BIS-15: Barratt Impulsiveness Scale

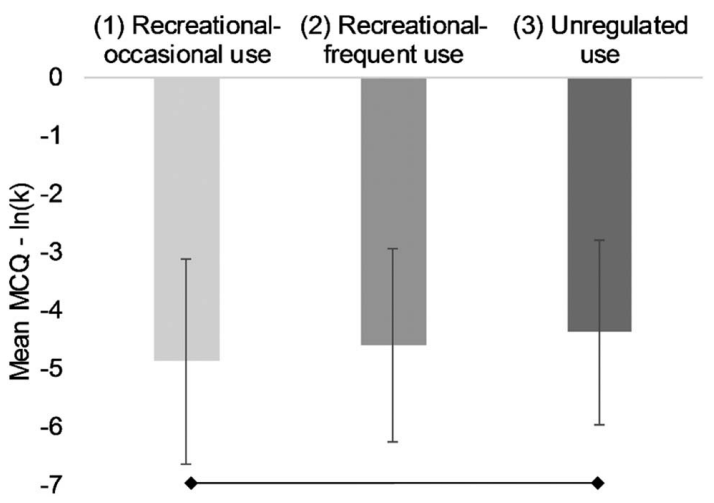

Figure 2. Mean values of MCQ measuring impulsive choice for groups of Internet pornography users. Higher values indicate more impulsive choice. Standard deviations are represented by the error bars attached to each column. MCQ: Monetary choice Questionnaire

for these factors, which might indicate that facets of impulsivity do not contribute substantially to an unregulated IP use. This result is consistent with the results by Böthe et al. (2018). Following the assumptions of the I-PACE model (Brand, Young, et al., 2016), it is possible that effects of these trait variables on the symptom severity are moderated or mediated by affective and cognitive responses. Accordingly, the factors associated with impulsive behavior may act in concert with affective and cognitive responses, especially in situations, when the user is confronted with pornographic cues or is in an abnormal mood (Brand, Young, et al., 2016). This might be an explanation for the low or non-significant effects of attentional, motor, and non-planning impulsivity, cognitive style, impulsive choice, and also functional and dysfunctional coping styles. In this context, impulsivity, measured with cognitive tasks, has been associated with compulsive sexual behavior and in interaction with trait impulsivity with symptom severity of unregulated IP use (Antons \& Brand, 2018; Miner, Raymond, Mueller, Lloyd, \& Lim, 2009). Future studies should address how these declarative factors measured in this study act in concert with situational affective and cognitive responses.

Furthermore, based on dual-process models (Bechara, 2005; Robinson \& Berridge, 1993; Volkow, Fowler, \& Wang, 2003), the group differences in craving and attitude toward IP may be indicative for increased bottom-up processes (also see neuroimaging studies by Brand, Snagowski, Laier, \& Maderwald, 2016; Gola et al., 2017; Voon et al., 2014). Functional coping styles and the cognitive style need for cognition represent factors involved in top-down processes, which were significantly lower in individuals with unregulated IP use. However, the effects were low. Thus, the results of this study allow the assumption that especially bottom-up processes are increased in males with unregulated IP use, contributing to more impulsive or addictive behaviors. Nevertheless, it has to be mentioned that symptom severity of unregulated use of further Internet applications was a significant covariate in most analyses. Therefore, the association between impulsivity and unregulated use of multiple Internet applications should be investigated in future studies.

A further interesting result is that the effect size for posthoc tests duration in minutes per session, when comparing unregulated users with recreational-frequent users, was higher in comparison to the frequency per week. This might 

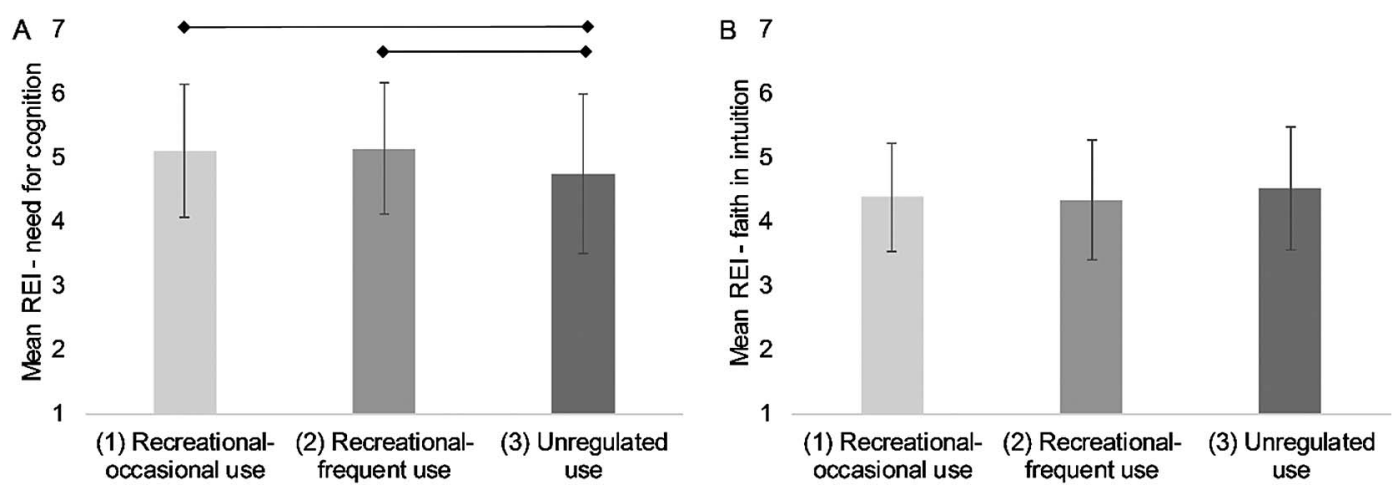

Figure 3. Mean values of cognitive styles as measured by the REI subscales for groups of Internet pornography users. Significant differences are indicated by the horizontal bars. Standard deviations are represented by the error bars attached to each column.

REI: Rational-Experiential Inventory
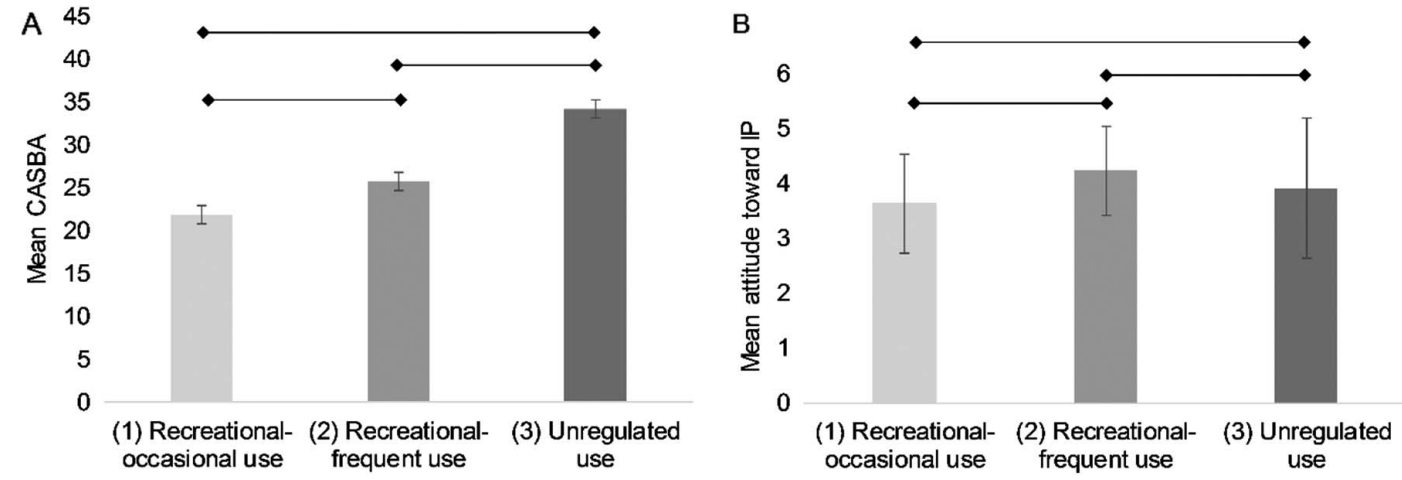

Figure 4. Mean values of (A) CASBA-porn measuring baseline craving and (B) attitude toward IP for groups of Internet pornography users. Significant differences are indicated by the horizontal bars. Standard deviations are represented by the error bars attached to each column.

CASBA: Craving Assessment Scale for Behavioral Addiction specified for Internet pornography use; IP: Internet pornography
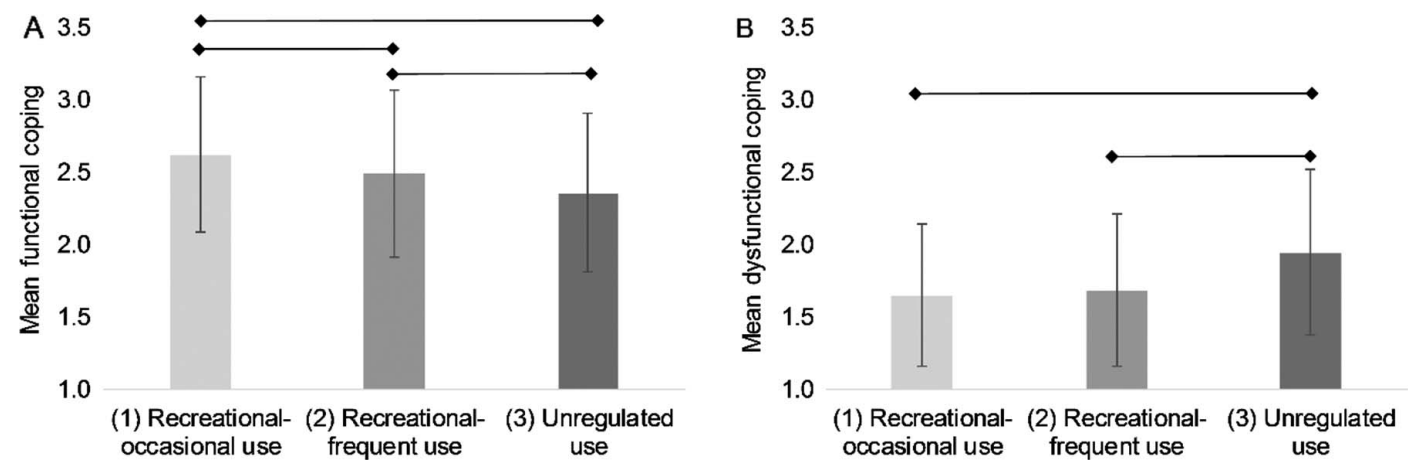

Figure 5. Mean values of (A) functional and (B) dysfunctional coping styles for groups of Internet pornography users. Significant differences are indicated by the horizontal bars. Standard deviations are represented by the error bars attached to each column

indicate that individuals with unregulated IP use especially have difficulties to stop watching IP during a session or need longer time to achieve the desired reward, which might be comparable with a form of tolerance in substance use disorders. This is consistent with the results from a diary assessment, which revealed that pornographic binges are one of the most characteristic behaviors in treatmentseeking males with compulsive sexual behaviors (Wordecha et al., 2018). Furthermore, the current results show that the amount of IP use is not sufficient to differentiate between recreational and unregulated IP users (also see Gola, Lewczuk, \& Skorko, 2016).
There are some limitations that need to be mentioned. First, the measures used to assess facets of impulsivity were not exhaustive. For example, we measured trait impulsivity but not impulsivity, for example, with cognitive tasks (Wingrove \& Bond, 1997). Furthermore, weekly IP usage time, on which basis groups were defined, was measured by a self-perceived estimate, which possibly leads to deviant data (Montag et al., 2015). In addition, there is the possibility of distinctive biases in data for individuals with recreational and unregulated IP use. Moreover, there are individuals who experience problems due to their IP use, even though the average time they use IP is low (Grubbs \& Perry, 2018; 
Vaillancourt-Morel et al., 2017). It has to be noted that cut-off scores used for s-IATporn have not been validated and cut-offs for IP use were based on the sample distribution. Future studies might also use person-centered methods (cluster analysis or latent profile analysis) to identify potential subgroups of IP users. One further limitation is that craving was assessed with a newly developed multi-item questionnaire, which has not been validated but which is presumably advantageous compared to single-item assessments (see reviews by Rosenberg, 2009; Tiffany \& Wray, 2012) and in contrast with the pornography-craving questionnaire by Kraus and Rosenberg (2014), more concisely assesses aspects of reward and relief craving. Finally, we only investigated heterosexual males. Important gender effects have been reported in previous studies (Bőthe, Koós, Tóth-Király, Orosz, \& Demetrovics, 2019; Gola et al., 2016; Lewczuk, Szmyd, Skorko, \& Gola, 2017). The results need to be replicated in samples of non-heterosexual orientation and females.

To conclude, it has been shown that high baseline craving and a more negative attitude toward IP are specific for an unregulated IP use in heterosexual males and not for recreational users. On the contrary, strong positive attitudes are specific for recreational-frequent IP users. The results are consistent with theories and models of (behavioral) addictions; however, since impulsivity and the urge to perform an act that is rewarding are also symptoms of impulse-control disorders, the results do not directly contribute to the discussion of classification. Future investigations should focus on differences between recreational-frequent IP users and individuals with unregulated IP use with regard to interactions between trait and state variables.

Funding sources: No financial support was received for this study.

Authors' contribution: SMM, EW, MB, and SA designed the study. Data collection was carried out by SA. EW, PT, and SA conducted the statistical analysis and interpreted the results. SA, SMM, and MMS wrote the first and final drafts of the manuscript. EW, PT, and MB revised the manuscript. MB supervised the interpretation of the data and writing of the manuscript. All authors had full access to all data, contributed to and have approved the final version of the manuscript.

Conflict of interest: The authors declare no conflict of interest.

\section{REFERENCES}

Antons, S., \& Brand, M. (2018). Trait and state impulsivity in males with tendency towards Internet-pornography-use disorder. Addictive Behaviors, 79, 171-177. doi:10.1016/j.addbeh. 2017.12.029

Bechara, A. (2005). Decision making, impulse control and loss of willpower to resist drugs: A neurocognitive perspective. $\mathrm{Na}$ ture Neuroscience, 8(11), 1458-1463. doi:10.1038/nn1584
Berridge, K. C., \& Robinson, T. E. (2016). Liking, wanting and the incentive-sensitization theory of addiction. The American Psychologist, 71(8), 670-679. doi:10.1037/amp0000059

Billieux, J., Gay, P., Rochat, L., \& Van der Linden, M. (2010). The role of urgency and its underlying psychological mechanisms in problematic behaviours. Behaviour Research and Therapy, 48(11), 1085-1096. doi:10.1016/j.brat.2010.07.008

Bőthe, B., Koós, M., Tóth-Király, I., Orosz, G., \& Demetrovics, Z. (2019). Investigating the associations of adult ADHD symptoms, hypersexuality, and problematic pornography use among men and women on a largescale, non-clinical sample. The Journal of Sexual Medicine, 16(4), 489-499. doi:10.1016/ j.jsxm.2019.01.312

Böthe, B., Tóth-Király, I., Orosz, G., Potenza, M. N., Griffiths, M. D., \& Demetrovics, Z. (2018). Revisiting the role of impulsivity and compulsivity in problematic sexual behaviors. The Journal of Sex Research, 56(2), 166-179. doi:10.1080/ 00224499.2018.1480744

Brand, M., Laier, C., \& Young, K. S. (2014). Internet addiction: Coping styles, expectancies, and treatment implications. Frontiers in Psychology, 5, 1256. doi:10.3389/fpsyg.2014.01256

Brand, M., Snagowski, J., Laier, C., \& Maderwald, S. (2016). Ventral striatum activity when watching preferred pornographic pictures is correlated with symptoms of Internet pornography addiction. Neuroimage, 129, 224-232. doi:10. 1016/j.neuroimage.2016.01.033

Brand, M., Young, K. S., Laier, C., Wölfling, K., \& Potenza, M. N. (2016). Integrating psychological and neurobiological considerations regarding the development and maintenance of specific Internet-use disorders: An Interaction of PersonAffect-Cognition-Execution (I-PACE) model. Neuroscience and Biobehavioral Reviews, 71, 252-266. doi:10.1016/j. neubiorev.2016.08.033

Brown, C. C., Conner, S., \& Vennum, A. (2017). Sexual attitudes of classes of college students who use pornography. Cyberpsychology, Behavior, and Social Networking, 20(8), 463-469. doi:10.1089/cyber.2016.0362

Carver, C. S. (1997). You want to measure coping but your protocol' too long: Consider the brief cope. International Journal of Behavioral Medicine, 4(1), 92-100. doi:10.1207/ s15327558ijbm0401_6

Cooper, A., Morahan-Martin, J., Mathy, R. M., \& Maheu, M. (2002). Toward an increased understanding of user demographics in online sexual activities. Journal of Sex and Marital Therapy, 28(2), 105-129. doi:10.1080/009262302 52851861

Cooper, A., Putnam, D. E., Planchon, L. A., \& Boies, S. C. (1999). Online sexual compulsivity: Getting tangled in the net. Sexual Addiction \& Compulsivity, 6(2), 79-104. doi:10.1080/ 10720169908400182

Curran, P. G. (2016). Methods for the detection of carelessly invalid responses in survey data. Journal of Experimental Social Psychology, 66, 4-19. doi:10.1016/j.jesp.2015.07.006

Dickman, S. J. (1990). Functional and dysfunctional impulsivity: Personality and cognitive correlates. Journal of Personality and Social Psychology, 58(1), 95-102. doi:10.1037/00223514.58.1.95

Epstein, S., Pacini, R., Denes-Raj, V., \& Heier, H. (1996). Individual differences in intuitive-experiential and analyticalrational thinking styles. Journal of Personality and Social Psychology, 71(2), 390-405. doi:10.1037/0022-3514.71.2.390 
Franc, E., Khazaal, Y., Jasiowka, K., Lepers, T., Bianchi-Demicheli, F., \& Rothen, S. (2018). Factor structure of the Cybersex Motives Questionnaire. Journal of Behavioral Addictions, 7(3), 601-609. doi:10.1556/2006.7.2018.67

Gola, M., Lewczuk, K., \& Skorko, M. (2016). What matters: Quantity or quality of pornography use? Psychological and behavioral factors of seeking treatment for problematic pornography use. The Journal of Sexual Medicine, 13(5), 815-824. doi:10.1016/j.jsxm.2016.02.169

Gola, M., Wordecha, M., Sescousse, G., Lew-Starowicz, M., Kossowski, B., Wypych, M., Makeig, S., Potenza, M. N., \& Marchewka, A. (2017). Can pornography be addictive? An fMRI study of men seeking treatment for problematic pornography use. Neuropsychopharmacology, 42(10), 2021-2031. doi:10.1038/npp.2017.78

Grubbs, J. B., \& Perry, S. L. (2018). Moral incongruence and pornography use: A critical review and integration. The Journal of Sex Research, 56(1), 29-37. doi:10.1080/00224499. 2018.1427204

Hald, G. M., \& Malamuth, N. M. (2008). Self-perceived effects of pornography consumption. Archives of Sexual Behavior, 37(4), 614-625. doi:10.1007/s10508-007-9212-1

Hasking, P., Lyvers, M., \& Carlopio, C. (2011). The relationship between coping strategies, alcohol expectancies, drinking motives and drinking behaviour. Addictive Behaviors, 36(5), 479-487. doi:10.1016/j.addbeh.2011.01.014

Jauregui, P., Onaindia, J., \& Estévez, A. (2017). Adaptive and maladaptive coping strategies in adult pathological gamblers and their mediating role with anxious-depressive symptomatology. Journal of Gambling Studies, 33(4), 1081-1097. doi:10.1007/s10899-017-9675-5

Jentsch, J. D., Ashenhurst, J. R., Cervantes, M. C., Groman, S. M., James, A. S., \& Pennington, Z. T. (2014). Dissecting impulsivity and its relationships to drug addictions. Annals of the New York Academy of Sciences, 1327, 1-26. doi:10.1111/ nyas. 12388

Keller, J., Bohner, G., \& Erb, H.-P. (2000). Intuitive und heuristische Urteilsbildung - verschiedene Prozesse? Präsentation einer deutschen Fassung des "Rational-Experiential Inventory" sowie neuer Selbstberichtskalen zur Heuristiknutzung [Intuitive and heuristic judgment - different processes? Presentation of a German version of the Rational-Experiential Inventory and of new self-report scales of heuristic use]. Zeitschrift für Sozialpsychologie, 31(2), 87-101. doi:10. 1024//0044-3514.31.2.87

Kirby, K. N., Petry, N. M., \& Bickel, W. K. (1999). Heroin addicts have higher discount rates for delayed rewards than nondrug-using controls. Journal of Experimental Psychology: General, 128(1), 78-87. doi:10.1037/0096-3445.128.1.78

Knoll, N., Rieckmann, N., \& Schwarzer, R. (2005). Coping as a mediator between personality and stress outcomes: A longitudinal study with cataract surgery patients. European Journal of Personality, 19(3), 229-247. doi:10.1002/per.546

Kraus, S. W., Krueger, R. B., Briken, P., First, M. B., Stein, D. J., Kaplan, M. S., Voon, V., Abdo, C. H. N., Grant, J. E., Atalla, E., \& Reed, G. M. (2018). Compulsive sexual behaviour disorder in the ICD-11. World Psychiatry, 17(1), 109-110. doi:10.1002/wps.20499

Kraus, S. W., Meshberg-Cohen, S., Martino, S., Quinones, L. J., \& Potenza, M. N. (2015). Treatment of compulsive pornography use with naltrexone: A case report. American Journal of
Psychiatry, 172(12), 1260-1261. doi:10.1176/appi.ajp.2015. 15060843

Kraus, S. W., \& Rosenberg, H. (2014). The pornography craving questionnaire: Psychometric properties. Archives of Sexual Behavior, 43(3), 451-462. doi:10.1007/s10508-013-0229-3

Laier, C., Pawlikowski, M., Pekal, J., Schulte, F. P., \& Brand, M. (2013). Cybersex addiction: Experienced sexual arousal when watching pornography and not real-life sexual contacts makes the difference. Journal of Behavioral Addictions, 2(2), 100-107. doi:10.1556/JBA.2.2013.002

Laier, C., Pekal, J., \& Brand, M. (2015). Sexual excitability and dysfunctional coping determine cybersex addiction in homosexual males. Cyberpsychology, Behavior, and Social Networking, 18(10), 575-580. doi:10.1089/cyber.2015.0152

Lewczuk, K., Szmyd, J., Skorko, M., \& Gola, M. (2017). Treatment seeking for problematic pornography use among women. Journal of Behavioral Addictions, 6(4), 445-456. doi:10.1556/ 2006.6.2017.063

Love, T., Laier, C., Brand, M., Hatch, L., \& Hajela, R. (2015). Neuroscience of Internet pornography addiction: A review and update. Behavioral Sciences, 5(3), 388-433. doi:10.3390/ bs5030388

Meade, A. W., \& Craig, S. B. (2012). Identifying careless responses in survey data. Psychological Methods, 17(3), 437-455. doi:10.1037/a0028085

Meule, A., Vögele, C., \& Kübler, A. (2011). Psychometrische Evaluation der deutschen Barratt Impulsiveness Scale - Kurzversion (BIS-15) [Psychometric evaluation of the German Baratt Impulsiveness Scale - Short version (BIS15)]. Diagnostica, 57(3), 126-133. doi:10.1026/0012-1924/a000042

Miner, M. H., Raymond, N., Mueller, B. A., Lloyd, M., \& Lim, K. O. (2009). Preliminary investigation of the impulsive and neuroanatomical characteristics of compulsive sexual behavior. Psychiatry Research: Neuroimaging, 174(2), 146-151. doi:10.1016/j.pscychresns.2009.04.008

Montag, C., Błaszkiewicz, K., Lachmann, B., Sariyska, R., Andone, I., Trendafilov, B., \& Markowetz, A. (2015). Recorded behavior as a valuable resource for diagnostics in mobile phone addiction: Evidence from psychoinformatics. Behavioral Sciences, 5(4), 434-442. doi:10.3390/bs5040434

Müller, M., Brand, M., Mies, J., Lachmann, B., Sariyska, R. Y., \& Montag, C. (2017). The 2D:4D marker and different forms of Internet use disorder. Frontiers in Psychiatry, 8(213), 213. doi:10.3389/fpsyt.2017.00213

Negash, S., Sheppard, N. V., Lambert, N. M., \& Fincham, F. D. (2016). Trading later rewards for current pleasure: Pornography consumption and delay discounting. Journal of Sex Research, 53(6), 689-700. doi:10.1080/00224499.2015.1025123

Pawlikowski, M., Altstötter-Gleich, C., \& Brand, M. (2013). Validation and psychometric properties of a short version of Young's Internet Addiction Test. Computers in Human Behavior, 29(3), 1212-1223. doi:10.1016/j.chb.2012.10.014

Potenza, M. N., Gola, M., Voon, V., Kor, A., \& Kraus, S. W. (2017). Is excessive sexual behaviour an addictive disorder? The Lancet Psychiatry, 4(9), 663-664. doi:10.1016/S22150366(17)30316-4

Reid, R. C., Li, D. S., Gilliland, R., Stein, J. A., \& Fong, T. (2011). Reliability, validity, and psychometric development of the Pornography Consumption Inventory in a sample of hypersexual men. Journal of Sex and Marital Therapy, 37(5), 359-385. doi:10.1080/0092623X.2011.607047 
Robinson, T. E., \& Berridge, K. C. (1993). The neural basis of drug craving: An incentive-sensitization theory of addiction. Brain Research Reviews, 18(3), 247-291. doi:10.1016/01650173(93)90013-P

Rosenberg, H. (2009). Clinical and laboratory assessment of the subjective experience of drug craving. Clinical Psychology Review, 29(6), 519-534. doi:10.1016/j.cpr.2009.06.002

Rosenberg, H., \& Kraus, S. (2014). The relationship of "passionate attachment" for pornography with sexual compulsivity, frequency of use, and craving for pornography. Addictive Behaviors, 39(5), 1012-1017. doi:10.1016/j.addbeh.2014.02.010

Rosenberg, H., \& Mazzola, J. (2007). Relationships among selfreport assessments of craving in binge-drinking university students. Addictive Behaviors, 32(12), 2811-2818. doi:10. 1016/j.addbeh.2007.04.019

Snagowski, J., \& Brand, M. (2015). Symptoms of cybersex addiction can be linked to both approaching and avoiding pornographic stimuli: Results from an analog sample of regular cybersex users. Frontiers in Psychology, 6, 653. doi:10.3389/ fpsyg.2015.00653

Snagowski, J., Wegmann, E., Pekal, J., Laier, C., \& Brand, M. (2015). Implicit associations in cybersex addiction: Adaption of an Implicit Association Test with pornographic pictures. Addictive Behaviors, 49, 7-12. doi:10.1016/j.addbeh.2015. 05.009

Starcke, K., Antons, S., Trotzke, P., \& Brand, M. (2018). Cuereactivity in behavioral addictions: A meta-analysis and methodological considerations. Journal of Behavioral Addictions, 7(2), 227-238. doi:10.1556/2006.7.2018.39

Svedin, C. G., Akerman, I., \& Priebe, G. (2011). Frequent users of pornography. A population based epidemiological study of Swedish male adolescents. Journal of Adolescence, 34(4), 779-788. doi:10.1016/j.adolescence.2010.04.010

Tiffany, S. T., \& Drobes, D. J. (1991). The development and initial validation of a questionnaire on smoking urges. British Journal of Addiction, 86(11), 1467-1476. doi:10.1111/j.1360-0443. 1991.tb01732.x

Tiffany, S. T., \& Wray, J. M. (2012). The clinical significance of drug craving. Annals of the New York Academy of Sciences, 1248(1), 1-17. doi:10.1111/j.1749-6632.2011.06298.x

Trizano-Hermosilla, I., \& Alvarado, J. M. (2016). Best alternatives to Cronbach's alpha reliability in realistic conditions: Congeneric and asymmetrical measurements. Frontiers in Psychology, 7, 769. doi:10.3389/fpsyg.2016.00769

Vaillancourt-Morel, M.-P., Blais-Lecours, S., Labadie, C., Bergeron, S., Sabourin, S., \& Godbout, N. (2017). Profiles of cyberpornography use and sexual well-being in adults. The
Journal of Sexual Medicine, 14(1), 78-85. doi:10.1016/ j.jsxm.2016.10.016

Verheul, R., van den Brink, W., \& Geerlings, P. (1999). A threepathway psychobiological model of craving for alcohol. Alcohol and Alcoholism, 34(2), 197-222. doi:10.1093/alcalc/34.2.197

Volkow, N. D., Fowler, J. S., \& Wang, G.-J. (2003). The addicted human brain: Insights from imaging studies. The Journal of Clinical Investigation, 111(10), 1444-1451. doi:10.1172/ JCI18533

Voon, V., Mole, T. B., Banca, P., Porter, L., Morris, L., Mitchell, S., Lapa, T. R., Karr, J., Harrison, N. A., Potenza, M. N., \& Irvine, M. (2014). Neural correlates of sexual cue reactivity in individuals with and without compulsive sexual behaviours. PLoS One, 9(7), e102419. doi:10.1371/journal.pone.0102419

Wegmann, E., \& Brand, M. (2016). Internet-communication disorder: It's a matter of social aspects, coping, and Internet-use expectancies. Frontiers in Psychology, 7, 1747. doi:10.3389/ fpsyg.2016.01747

Weinstein, A. M., Zolek, R., Babkin, A., Cohen, K., \& Lejoyeux, M. (2015). Factors predicting cybersex use and difficulties in forming intimate relationships among male and female users of cybersex. Frontiers in Psychiatry, 6(54), 54. doi:10.3389/ fpsyt.2015.00054

Wéry, A., Deleuze, J., Canale, N., \& Billieux, J. (2017). Emotionally laden impulsivity interacts with affect in predicting addictive use of online sexual activity in men. Comprehensive Psychiatry, 80, 192-201. doi:10.1016/j.comppsych.2017. 10.004

Wetterneck, C. T., Burgess, A. J., Short, M. B., Smith, A. H., \& Cervantes, M. E. (2012). The role of sexual compulsivity, impulsivity, and experiential avoidance in Internet pornography use. The Psychological Record, 62(1), 3-18. doi:10.1007/ BF03395783

Wingrove, J., \& Bond, A. J. (1997). Impulsivity: A state as well as trait variable. Does mood awareness explain low correlations between trait and behavioural measures of impulsivity? Personality and Individual Differences, 22(3), 333-339. doi:10. 1016/S0191-8869(96)00222-X

Wordecha, M., Wilk, M., Kowalewska, E., Skorko, M., Łapiński, A., \& Gola, M. (2018). "Pornographic binges" as a key characteristic of males seeking treatment for compulsive sexual behaviors: Qualitative and quantitative 10-week-long diary assessment. Journal of Behavioral Addictions, 7(2), 433-444. doi:10.1556/2006.7.2018.33

Young, K. S. (2008). Internet sex addiction: Risk factors, stages of development, and treatment. American Behavioral Scientist, 52(1), 21-37. doi:10.1177/0002764208321339 